\title{
Mulheres e filhos encarcerados: uma realidade institucional
}

\section{Incarcerated women and children: an institutional reality \\ Mujeres e hijos encarcelados: una realidad institucional}

\section{Ilka Franco Ferrari*}

Pontifícia Universidade Católica de Minas Gerais - PUC Minas, Belo Horizonte, Minas Gerais, Brasil

\section{Bárbara Morais Fam**}

Pontifícia Universidade Católica de Minas Gerais - PUC Minas, Belo Horizonte, Minas Gerais, Brasil

\begin{abstract}
RESUMO
Este artigo traz informações provenientes da primeira pesquisa realizada no "Centro de Referência à Gestante Privada de Liberdade", instituição prisional para mães e bebês, inaugurada em 2009, na cidade de Vespasiano, Minas Gerais. Trata-se de instituição criada com o propósito de humanizar a situação de grávidas e lactantes encarceradas com seus filhos, e é considerada modelo para a América Latina. Nesta pesquisa, realizada nos moldes de pesquisa participante, o Centro de Referência foi considerado o objeto a ser estudado, e aqui são apresentados dados da etapa de conversações realizadas com prisioneiras e funcionárias, tal como a psicanálise as propõe. Inicialmente são pontuadas algumas interfaces entre a psicanálise e o campo jurídico, e a partir disso delineia-se a construção do texto de regras da instituição pesquisada para, em seguida, trazer recortes das conversações. As falas evidenciam o texto de regras da unidade sendo desconstruído pelos sujeitos nela inseridos, e revelam um fato no mínimo curioso: a maioria das mulheres preferia estar em uma instituição prisional comum.
\end{abstract}

Palavras-chaves: prisioneiras, mães, bebês, psicanálise, direito.

\begin{abstract}
This article brings information from the first research realized in the "Reference Center to the Pregnant Deprived of Liberty", prison institution for mothers and babies, inaugurated in 2009, at Vespasiano City, Minas Gerais. It is an institution created with the purpose of humanizing the incarcerated pregnant and lactiferous situation with their children, and it is considered a model to the Latin American. It is performed in the format of participant survey, on this research the Reference Center was considered the object of study and here are presented data of the step of conversations realized with the prisoners and employees, such as the psychoanalysis propose. At first some interfaces between psychoanalysis and juridical field are punctuated and from that it is outlined the construction of the researched institution rule
\end{abstract}


text to, after that, bring a cutting of the conversations. The lines spotlight the unity rule text being deconstructed by the subjects inserted in there, and reveal a fact that is at least curious: the majority of the women rather be in a regular prison institution.

Keywords: prisoners, mothers, babies, psychoanalysis, law.

\section{RESUMEN}

Este artículo proporciona informaciones de la primera investigación llevada a cabo en el "Centro de Referencia para la Mujer Embarazada Privada de Libertad", institución carcelaria para madres y bebés, inaugurada en 2009, en la ciudad de Vespasiano, Minas Gerais. Se trata de una institución creada con el propósito de humanizar la situación de las mujeres embarazadas y lactantes encarceladas con sus hijos, que se considera un modelo para América Latina. En esta investigación, realizada en los moldes de la investigación participante, el Centro de Referencia fue considerado el objeto a ser estudiado, y aquí son presentados los datos de la etapa de las conversaciones efectuadas con prisioneras y funcionarias, tal y como el psicoanálisis las propone. Inicialmente son señalados algunos puntos de contacto entre el psicoanálisis y el ámbito jurídico, y a partir de ahí se delinea la construcción del texto de las normas de la institución investigada para, acto seguido, exponer algunas partes de las conversaciones. Los diálogos muestran como el texto de reglas de la unidad es deconstruido por los sujetos en ella inseridos, y revelan un hecho como mínimo curioso: la mayor parte de las mujeres prefería estar en una institución carcelaria común.

Palabras clave: prisioneras, madres, niños, psicoanálisis, derecho.

A escrita desse texto surge a partir da pesquisa "Mulheres encarceradas: laços com o crime, desenlace familiar", concluída em 2014. Ela teve como objetivo geral a investigação do "Centro de Referência à Gestante Privada de Liberdade", com cinco anos de funcionamento, em Vespasiano, MG, localizando-o como uma resposta social às questões do mal-estar na civilização atual, a partir do aprisionamento das mulheres e seus filhos. Situação que, obviamente, instaura questões diversas sobre formas de laços sociais e modos sintomáticos de vida que convocam as políticas públicas atuais.

Um trabalho como esse exige que a realidade social seja refletida, considerada, e que possibilidades de diálogos com áreas implicadas sejam abertas. Nesse caso, não há como duvidar que é necessária uma interlocução entre psicanálise e direito. E como houve o compromisso de devolução das informações para a instituição e autoridades envolvidas no seu dia a dia, esse texto traz, inicialmente, algumas considerações úteis para seu desenrolar, acerca dessa interlocução possível. Ele aborda, a partir daí, recortes da extensa pesquisa realizada na instituição prisional, não sem antes esclarecer seus procedimentos. 


\section{A sina humana para transgressões: a psicanálise em interface com o campo jurídico}

Em qualquer sociedade são necessários dispositivos para delimitar o que é proibido, e isso não resulta de difícil constatação. Em psicanálise, quando se trata de temas como esse, fica viva a afirmação de Lacan de que o castigo é mesmo "uma característica essencial da ideia do homem que prevalece numa dada sociedade" (Lacan, 1998, p. 839). Cada qual com suas formas de delimitar e punir o que foge ao estabelecido para a convivência em comum.

Miller (1991, p.19) relembra que Lacan, a partir dos percursos freudianos, "nunca renunciou à ideia de que, no nível profundo, o que há é a hostilidade e não a harmonia", referindo-se aos laços entre humanos. Os atos criminosos, lidos sempre tendo a realidade social da época no horizonte, são modos de dizer de dificuldades diante do impasse entre lei, gozo e Outro (Ferrari, 2012). Consequentemente, importa ao profissional implicado com a psicanálise, a indagação sobre a subjetividade dos sujeitos envolvidos nesses atos, operando com ética que valoriza a responsabilidade subjetiva e difere da responsabilidade penal, sem a desprezar. Isso porque, ao campo do direito cabe a importante tarefa de, por exemplo, determinar como serão julgados e punidos os cidadãos, já que em qualquer sociedade sempre ocorrerão transgressões do estabelecido.

Em se tratando das instituições que compõem certa sociedade, podese dizer que elas não existem sem regras construídas por sujeitos engajados e, também, sem estar à mercê de desconstrução advinda dos sujeitos ali inseridos, seja para renovações de qualquer caráter ou para seu desaparecimento histórico. Elas funcionam, portanto, como um texto de regras que os sujeitos podem desconstruir, tal como ensina Laurent (2003).

O "Centro de Referência à Gestante Privada de Liberdade" possui seu texto de regras considerado útil para uma segregação necessária de mães/mulheres e seus filhos prisioneiros. E encontra espaço entre mais um sintoma social, ou seja, como aquilo que diz do que não funciona em certa ordem estabelecida pela sociedade, por exemplo, em seus ideais democráticos e igualitários. Trata-se de uma resposta da sociedade para avatares que Ihe são inerentes, mas, em sua operacionalização, como pode ocorrer, já não consegue evitar vozes que sussurram ou até gritam pontos cruciais, fora do eixo em que se sustentaram os ideais na época de sua criação. O mal-estar procedente do cotidiano no cárcere, e das especificidades do "Centro de Referência" impõe, consequentemente, formas de laço social e modos de vida, convocando novas ou renovadas ações de políticas públicas.

Freud (2006), em O mal-estar na civilização, já abordava a relação conflituosa entre indivíduo e sociedade, e ali fica explícita sua ideia de 
que a agressividade é inerente à condição humana: "Como já sabemos, o problema que temos pela frente é saber como livrar-se do maior estorvo à civilização - isto é, a inclinação, constitutiva dos seres humanos, para a agressividade mútua" (Freud, 2006, p.145). Ele considerava a existência de dificuldades para que o indivíduo submeta, a um manejo possível para o convívio social, sua inclinação à agressividade. Por outro lado, reconhecia que a ordem social implica, sempre, a necessidade do estabelecimento de leis e regras pactuadas entre os integrantes do grupo, processo que acaba por manter a dinâmica de conflito entre o humano e o social.

Lacan seguiu com essa concepção de que a agressividade diferentemente de violência - é inerente à condição humana. Segundo Miller (1991), as ideias de Lacan a respeito da constituição do sujeito, da castração, do supereu e do Outro podem comprovar isso. Não sem razão, portanto, Lacan é considerado um dos percursores do campo da criminologia psicanalítica, como assegura Birman (2006), o que pode ser constatado na tese de doutorado do psicanalista francês Da psicose paranoica em suas relações com a personalidade, de 1932, na narrativa Motivos do Crime Paranoico: O Crime das Irmãs Papin, de 1933, em seu ensaio O estádio do espelho como formador da função do eu, de 1949, em A agressividade em psicanálise, de 1948, e em seu texto Introdução teórica às funções da psicanálise em criminologia, de 1950. Ainda segundo Birman (2006), a questão que atravessa todos esses textos de Lacan é o conflito entre os registros do corpo fragmentado e do corpo unificado, ou seja, a dimensão paranoica que marca o eu e regula a agressividade.

No artigo intitulado Criminologia Lacaniana, Serge Cottet (2008) faz uma releitura do texto lacaniano Contribuições teóricas às funções da psicanálise em criminologia (1950), buscando atualizá-lo. Segundo o autor, esse artigo faz parte do período "sociológico", pré-estruturalista de Lacan, que aconteceu entre os anos de 1938 a 1950, antes do Congresso de Roma. Neste período podem-se ouvir ecos do texto Os complexos familiares na formação do indivíduo, e de sua inspiração durkheimiana. Cottet (2008) explica que esse escrito orienta uma clínica do ato criminoso, uma vez que apresenta uma dialética do crime e da lei, bem como mostra a relevância do conceito de responsabilidade, para a psicanálise, em interface com a criminologia.

Ao considerar as referências lacanianas, e ler Cottet (2008), Salum (2009) promove contribuições da psicanálise para a criminologia, a partir do cenário da violência contemporânea no Brasil. Segundo a autora, se para o direito penal a responsabilidade é a possibilidade de imputação de uma pena, para a psicanálise ela é concebida como resposta de um sujeito, o que muda completamente o foco de ação. Daí, compete à psicanálise, na interface com o direito penal, acompanhar a possibilidade, ou não, de que o sujeito possa, através 
do castigo, promover a assunção de sua responsabilidade. Por isso, para a psicanálise, a responsabilidade é universal. A responsabilidade é o chamado para que o sujeito possa responder, frente aos seus semelhantes pelo ato que praticou (Salum, 2009, p. 171).

A era atual, como tantos já escreveram, é a da abundância de objetos de gozo, da pluralização dos significantes, do declínio dos ideais, da ascensão dos objetos de consumo, época em que se pode ter vergonha de muita coisa, até do desejo, mas não do gozo (Miller, 2003b). Cada vez mais a relação com o objeto não se faz pelo desejo, nesse mundo do discurso capitalista e do declínio do Nomedo-Pai, e instituições que anteriormente tinham a função de enlaçar o desejo à lei encontram suas dificuldades. A partir disso, Salum (2009, p.112) pergunta: "como sustentar a responsabilidade na época do Outro que não existe, numa época que preconiza a satisfação sem restrições?".

No caminho de responder sua própria pergunta, comenta que a realidade social contemporânea implica em mudanças na configuração dos crimes, pois, cada vez mais eles demonstram ruptura com o campo do Outro, com a rede de significantes. O que implica, também, em mudanças na possibilidade de responder, diante do Outro da lei. Assim sendo, permanece o desafio contemporâneo de sustentar a psicanálise como avesso do discurso do mestre, na clínica dos atos criminosos. A lógica subjacente aos crimes cometidos nos dias atuais é a do excesso. E no Centro de Referência o que mais se encontrou foram mulheres no mundo das drogas. Vale ressaltar que a questão em jogo não pode ter o ideal de provocar vergonha nesses sujeitos ou em outros, nesse mundo onde ela está em falta; em orientação psicanalítica, nem mesmo culpabilizá-los, pois isso consistiria em uma tentativa fracassada de restituir o significantemestre. Ocupar o lugar do "não saber" pode ser proveitoso, dando oportunidade de advir um sujeito que possa se responsabilizar por seu gozo, inventando soluções, modos de saber-fazer com seus sintomas, inclusive no campo jurídico.

Nessa perspectiva, é fácil seguir Miller (2005, p. 18) em suas considerações de que a civilização é um sistema de distribuição de gozo a partir de semblantes, é um modo de gozo, "uma repartição sistematizada dos meios e maneiras de gozar". Nossa sociedade, por sua vez, muito se caracteriza pela ditadura do mais-de-gozar, para o mais além do prazer que se encontra com a pulsão de morte, como adverte Ramirez (2007). E o Centro de Referência é uma das muitas instituições que surgem como forma de resposta política ao sistema de distribuição de modos de gozo de nossa civilização. De alguma maneira, essa instituição denuncia que algo não vai bem no que diz respeito ao encarceramento de grávidas e lactantes, na realidade social em que vivem. 


\section{Instituição resposta ao mal-estar social atual, seu texto de regras e a pesquisa}

Em 2007 chegaram denúncias à Comissão Interamericana de Direitos Humanos sobre os locais de encarceramento de gestantes e lactantes. Em geral, as mães ficavam encarceradas com seus filhos em locais com péssimas condições para se viver uma gravidez, o pósparto e o início de vida de uma criança, o que fere o Estatuto da Criança e Adolescente (ECA).

O Brasil, embora se diferencie de outros países da América Latina por possuir um conjunto de leis para consagração de direitos dos prisioneiros, a exemplo da Lei de Execução Penal (Lei no 7.210, 1984), continuamente viola estes direitos, principalmente quando se trata de segmentos menos favorecidos da população. Isso é o que se pode ler no Relatório Final para Reorganização e Reformulação do Sistema Prisional (Brasil, 2007a) e no Relatório sobre mulheres encarceradas no Brasil (Brasil, 2007b). Foi diante dessa situação que o então Presidente da República, Luiz Inácio Lula da Silva, em 28 de maio de 2009, sancionou o Projeto de Lei no 11.942, garantindo maior assistência às detentas grávidas ou mães com filhos menores que sete anos.

No que se refere à situação do estado de Minas, nos anos 2007-2008 (período em que o Centro de Referência foi idealizado), o sistema prisional comportava 215 internas no Complexo Feminino Estevão Pinto, localizado no Município de Belo Horizonte. Essa era a única Unidade Prisional com creche interna para abrigar, no máximo, 20 recém-nascidos. A demanda era sempre maior. O Presídio Feminino do Município de Ribeirão das Neves tinha capacidade para 130 mulheres e não contava com estrutura física para permanência de recém-nascidos. Havia, portanto, carência de infraestrutura e locais específicos para abrigar mulheres gestantes, parturientes e mães com bebês.

O Centro de Referência surgiu, então, como projeto, antecipando o Projeto de Lei do presidente Lula, com o objetivo geral de ampliar o Sistema Prisional do estado no que diz respeito a mulheres nessa situação, implementando políticas de saúde da mulher e da criança, com programa efetivo de atendimento em atenção básica, conforme Portaria Interministerial 1777/03, garantindo o acesso e melhora da qualidade dos serviços de atenção pré-natal e perinatal, bem como assegurando a reintegração da mulher no convívio social e familiar, após o cumprimento da pena (Minas Gerais, 2007). Na época de sua implantação, a imprensa e as autoridades governamentais ressaltavam que o Centro era o primeiro presídio do país, construído para grávidas e seus bebês, e o único da América Latina a abrigar gestantes a partir do sétimo mês, ou mães com seus bebês, em instalações sem grades. 
Sua instalação ocorreu por meio de adaptações feitas na estrutura de um hospital psiquiátrico desativado, denominado "Hospital Serra Verde", com planejamento para abrigar 35 presas e seus bebês. Nestes poucos anos de funcionamento, entretanto, chegou a acolher mais de 50 mulheres, o que levou à sua ampliação, e no período da pesquisa havia 56 mulheres reclusas. Em seu projeto de idealização (Minas Gerais, 2007) consta que as mulheres podem permanecer com seus filhos até completarem 12 meses, mas este tempo pode ser diminuído, por exemplo, no caso da prisioneira receber liberdade definitiva antes, ou estendido, no caso de dificuldades do juiz para estabelecer a guarda da criança. Trata-se, assim, de importante local de passagem, já que as detentas voltam para os presídios de origem, caso não obtenham liberdade, e os filhos são enviados para guardiões determinados pelo juiz. Há, portanto, casos de exceção tanto para a entrada (se as grávidas precisam de assistência especial, por exemplo) como para a saída. Nos documentos consultados não há clareza do motivo para estabelecimento desta temporalidade.

Uma das peculiaridades do presídio é que as internas são acompanhadas por uma equipe multidisciplinar, atualmente menor que a idealizada. Na época de execução da pesquisa não havia um médico fixo, apenas um clínico geral que visitava o Centro periodicamente. A equipe contava também com uma advogada, uma psicóloga, uma assistente social, uma enfermeira e técnicas de enfermagem, além das agentes penitenciárias. A equipe multidisciplinar, segundo projeto (Minas Gerais, 2007), deve trabalhar os vínculos afetivos de mães e filhos, a capacitação em cuidados gerais da criança, noções de puericultura e higienização. Há, ainda, o que consideram ser um trabalho de preparação para o processo de separação de mãe e filho respeitando "os princípios do superior interesse da criança definido pelo Estatuto da Criança e do Adolescente e Normas Mundiais de Saúde" (Minas Gerais, 2007).

No projeto consta, também, a determinação de que as agentes penitenciárias devem ser técnicas em enfermagem, ademais de serem capacitadas para serviço de segurança. Isso possibilitaria, segundo os idealizadores da instituição, pronto atendimento em casos de emergência e demandas de pré e pós-parto, cuidados com o recém-nascido na amamentação, cura do umbigo e doenças de menor gravidade.

E foi nesse jovem Centro de Referência, considerado um caso a ser estudado, e assentada no método de pesquisa intervenção, que permite a ignorância fecunda do pesquisador, que a pesquisa aconteceu. Na primeira fase da pesquisa realizou-se análise do discurso presente nas fichas institucionais, o "Prontuário Jurídico" e o "Prontuário de Saúde", da área psicológica, pois era importante conhecer a realidade social das detentas da ocasião pesquisada, construindo um amplo perfil das mesmas, e já publicado (Ferrari \& 
Machado, 2014). Na segunda, utilizou-se a "metodologia de conversação" (Miller, Alvarez \& Chang, 2003), com grupos de encarceradas e funcionárias.

A psicanálise esteve presente como bússola orientadora das discussões dos resultados, já que a metodologia da conversação é oriunda do método clínico freudiano, estruturada a partir da associação livre, que tem se mostrado como recurso fecundo de aplicação da psicanálise a diversos contextos sociais. Trata-se de um procedimento grupal em que os participantes debatem sobre tema proposto e, por meio da experiência com a palavra como um dom, o dizer de um ressoa no outro que também se coloca a trabalho. Este procedimento se sustenta no princípio de não se ter um saber prévio que conduz o trabalho, leva em consideração a dimensão do sujeito, ainda que em grupo, pois considera a existência de uma associação livre que é coletivizada e dela pode-se isolar pontos para análise. E, no modo psicanalítico de trabalhar, os sintomas do sujeito e do Outro somente permitem análise quando os sujeitos podem se expressar: "A conversação é uma prática da palavra para tratar manifestações indesejadas" (Santiago, 2011, p.97), ou seja, o que não vai bem, formulado por meio de queixas.

A pesquisa foi aprovada por Comitê de Ética, e todos participantes assinaram o Termo de Consentimento Livre e Esclarecido, conforme a Resolução CNS 196/96, vigente na época. Concordaram com as gravações e foram acordados os dias dos próximos encontros. A diretora da instituição auxiliou na escolha do melhor dia, horário e local para realização do convite para participação nas conversações, tanto para as detentas quanto funcionários.

A primeira conversação, realizada com detentas e funcionárias, foi a "conversação diagnóstica" (Santiago, 2011), em dias e horários diferentes. Não houve presença de funcionários homens, embora houvesse interesse, em função de sempre estarem em atividades nos horários combinados. A partir do livre uso da fala levantaram-se os pontos cruciais, sintomáticos, daquilo que não caminhava bem, sintoma do Outro que, por sua vez, sinalizava a falha no laço social. Esses pontos cruciais foram o marco para as três conversações posteriores, sem desconsiderar a importância daquilo que se ouviria em cada encontro e que poderia orientar outros rumos, distintos daqueles estabelecidos.

Vale ressaltar que as detentas que decidiram participar acreditavam na perspectiva de que a pesquisa pudesse levar modificações para a estrutura do funcionamento institucional. Sensibilizou-as saber que a pesquisa seria entregue às instâncias governamentais interessadas, à diretoria do Centro e até a elas mesmas. Na posição de segregadas pelo crime, de 'lixo humano' para as autoridades, como uma se expressou, havia o desejo de serem ouvidas para além dos muros do 
presídio, havia o desejo de que algo pudesse ser feito para os que ali ingressassem, ainda que elas mesmas já houvessem saído.

O espaço possível para os encontros com as detentas era um pátio invadido pelo sol, ao lado de um corredor onde uma televisão ficava ligada. Por ali circulavam outras detentas e suas crianças, funcionários, agentes, alguns destes tomando posição fixa no local, embora houvesse acordo com a diretoria para que isso não acontecesse. O dia, o local e os horários dos encontros foram planejados com a diretora da instituição, momento em que se esclareceu a importância de um pouco de privacidade para a boa realização do trabalho. Diante da impossibilidade de não haver agentes por perto, pediu-se que elas permanecessem mais distanciadas, o que não aconteceu. Na primeira conversação estiveram presentes 23 detentas. Nas seguintes, cerca de 19 em cada uma porque, como explicaram, as aulas haviam retornado, e alguns filhos adoeceram. Diz-se "cerca de", porque o espaço era aberto, e algumas chegavam, ouviam algo, assinalavam concordância com a cabeça, diziam algo e saíam, não podiam ficar. Outras se aproximavam, ouviam e se retiravam. Algumas voltavam, e outras não.

O local dos encontros com as funcionárias era uma pequena sala de espera, em parte também invadida pelo sol, situada no espaço de atendimento da Enfermagem. Por ali também vinha ou passava uma ou outra pessoa, mas permitia melhor funcionamento do trabalho. Dado importante é que, a princípio, todos os funcionários, embora liberados pela diretoria, pareciam impossibilitados de participar da pesquisa. Não era simples deixarem seus postos e, não raro, aquelas que participavam diziam do esforço para estar ali, e eram chamadas para voltar a seus encargos, com a conversação já iniciada, mas mantendo com empenho, desejo decidido, a participação. As conversações contaram com a participação de 6 (seis) funcionárias.

\section{Prisioneiras e funcionárias: a desconstrução de seu texto de regras institucional}

As informações obtidas nas conversações foram trabalhadas a partir da análise do discurso, de acordo com Gill (2013, p.244), considerando "uma rejeição da noção realista de que a linguagem é simplesmente um meio neutro de refletir, ou descrever o mundo, e uma convicção da importância central do discurso na construção da vida social".

Neste momento apresentam-se alguns recortes das informações obtidas, que dizem respeito ao modo sintomático dos sujeitos ali inseridos lidarem com o funcionamento institucional. 
$\mathrm{Na}$ fala das detentas, muitas queixas e críticas. A grande maioria declarou que preferia não estar ali, e sim em um presídio comum, fato que impressionou os pesquisadores. As justificativas que apresentam dizem respeito, principalmente, às condições a que seus filhos estão submetidos devido a um crime que foi praticado por elas. Uma delas diz: "eu roubei, é verdade, estou pagando pelo meu erro, como todo mundo está pagando pelo seu, mas as crianças não fizeram nada, nem as que estão na barriga da gente. Esses meninos sofrem aqui" (Detenta, 2013).

Um exemplo mencionado como forma de retratar esse sofrimento, consiste no fato da criança também ter que passar pelos procedimentos de revista ao entrar e sair do refeitório. Mencionam o caso de uma menina que já estava ali fazia um ano e oito meses, e que constantemente ficava abaixando a fralda, tal como exigido no momento do procedimento de revista. Uma prisioneira afirma ser um momento constrangedor para elas, enquanto mães, pois supõe que seriam capazes de esconder algo, na intimidade das roupas dos filhos.

Quando a pesquisadora Ihes diz que, para ela, é difícil imaginar como estar em uma cela pode ser melhor que estar ali, uma resposta vem rapidamente: "é porque, aqui, a gente fica com as crianças, mas, no nosso caso, aqui, a gente tá longe da família, a gente tem que fazer pra nós e pro nosso filho" (Detenta, 2013). Algumas que são do interior, e não são poucas, afirmam como razão da preferência de estar em outra unidade, a distância da família, de outros filhos que encontram dificuldades para visitá-las: "é ruim pra gente porque a maioria das pessoas aqui mora longe..., tenho mais dois meninos lá fora e vai fazer sete meses que eu não vejo meus filhos, é muito difícil" (Detenta, 2013). Assim, algumas dizem querer entregar o filho logo, com a finalidade de retornar ao presídio de origem, e reclamam da demora no processo de decisão judicial pela guarda da criança.

Foi nessa direção que uma das internas chegou a afirmar que a pressão dentro de um "quadrado" chega a ser bem menor que no Centro: "no fechado, até o psicológico da gente é menos abalado" (Detenta, 2013). E, a esse respeito, fato com o qual outras concordaram, elas explicaram que na cadeia fechada a convivência é mais fácil: "se acontecer alguma coisa entre as presas ali, elas se resolvem entre elas" (Detenta, 2013). Em relação às dificuldades, uma fala, outra completa, outra confirma, e assim seguem: "o sofrimento aqui é maior" (Detenta, 2013); "eu tenho problema de depressão, sabe? É foda, o choro de criança me incomoda" (Detenta, 2013);

aqui é uma querendo atrasar a outra... Se a gente tá na mesma situação, a gente tem que se unir. Aqui é uma querendo atrapalhar a outra! Dentro da cela da penitenciária de 
onde a gente veio são seis pessoas só dentro do convívio, então fica bem mais fácil (Detenta, 2013).

As mulheres ressaltaram a dificuldade de criar um filho "sozinha em um lugar como aquele". A criança sempre está "grudada" em seus corpos, por onde vão, pois ali são mães $24 \mathrm{~h}$ por dia, chegando a pontos insuportáveis, para a maioria. Somente uma detenta disse preferir estar ali, a todo custo, com o filho, a estar em outro local. Essas falas também não deixaram de surpreender pela força de expressão implicada e pela diferença que mostram, daquilo que se pretende no projeto.

A partir das análises dessas falas, foi possível isolar alguns motivos para a afirmação da maioria que preferia ficar reclusa em um presídio comum: a falta de um médico pediatra ou obstetra fixo; o sofrimento proveniente de ver o filho sentindo-se doente; instalações mofadas com goteiras por todos os lados e água saindo até pelas tomadas; presença de ratos em ambiente onde se guarda fraldas; escassez de atividades para as crianças, que permanecem o tempo todo grudadas em seus corpos, tal como dizem; desassistência e ignorância da equipe de enfermagem diante de certas dores ou sintomas sentidos, alguns depreciados levando à correria para a maternidade, com uma delas dando à luz dentro da ambulância. Vale ressalvar que a primeira leva de agentes que chegou para trabalhar no Centro de Referência havia passado por um treinamento da área de saúde, conforme previsto no projeto, entretanto, com a saída dessas e entrada de novas, esse treinamento não aconteceu mais.

Com relação aos pontos positivos da instituição, identificou-se: a proximidade que a estrutura e o funcionamento institucional possibilitam entre elas e a criança; a boa alimentação; o tratamento respeitoso por parte da maioria dos agentes e o trabalho realizado pela psicóloga, pela assistente social e pela pedagoga. Pontos que permitem que uma delas afirme que ali prisioneiras são tratadas "como seres humanos". Outra interna declarou, a respeito do período em que esteve reclusa em outra unidade: "foi o maior sofrimento que eu já passei na minha vida, depois que eu vim pra cá, melhorou muito! Aqui pelo menos eu saio, eu tomo um ar, não fico trancada 24 horas" (Detenta, 2013).

As funcionárias que estiveram nas conversações conhecem as queixas mencionadas, reconhecem a necessidade de algumas melhorias e reformas na instituição, mas, creem que esta posição queixosa, muito típica das detentas daquela atualidade, não tem fundamento:

eu, no meu modo de pensar, elas tinham que agradecer, porque elas estão muito bem assistidas, só que elas estão insatisfeitas. Quem me dera eu ter a minha filha e quando ela 
passava mal, eu ter meia noite a técnica de enfermagem pra dar remédio pra ela (Funcionária, 2013).

$\mathrm{Na}$ fala das funcionárias, um dos motivos que levavam as internas a desejarem ir para outra unidade é a distância da família, para as que são oriundas de outros municípios, e o cigarro, já que ali é permitido somente um por dia. As outras circunstâncias que apareceram no discurso das internas não foram mencionadas.

É consenso, entre as funcionárias que participaram da pesquisa, que o convívio no Centro de Referência, de forma geral, é tranquilo e que há um respeito recíproco entre agentes e prisioneiras. Uma delas, entretanto, afirma a necessidade da agente se impor para que as prisioneiras entendam que ali é um presídio, e elas não são suas colegas, ainda que brinquem e peguem seus filhos no colo. Uma delas diz:

porque é muito fácil, aqui tem criança, criança é bonitinha, meiguinha e faz gracinha, a gente brinca e tudo mais, e isso não pode ser confundido. Porque aqui tem norma, aqui tem regra, aqui tem horário, e às vezes elas precisam ser lembradas dessas normas, dessas regras, porque elas esquecem (Funcionária, 2013).

Aparece a história de detentas que pedem para as agentes segurarem seus filhos "um pouquinho, como se fossem suas empregadas", e o caso de uma que fez isso e não voltava. Quando a encontraram ela dormia, o que irritou tremendamente a agente em questão.

\section{Entre queixas e críticas, renovações possíveis}

Nesse processo os sujeitos implicados foram ouvidos a respeito das sugestões que visavam solucionar problemas levantados. E elas vieram tanto das funcionárias quanto das detentas. As funcionárias levantaram a necessidade de treinamentos mais adequados para agentes; contratação de um pediatra para trabalhar fixo; creche para as crianças das detentas e funcionários; parcerias com universidades para estagiários de áreas como medicina, enfermagem, assistência social, direito e psicologia. Uma delas, nesse momento, faz uma observação crucial, com certo ar de incógnita: ali as crianças se desenvolvem bem fisicamente, a alimentação é bem cuidada, mas, levam muito tempo para falar. Há, ainda sugestão de ampliação no quadro de agentes para atender a demanda de escoltas, já que são poucas e sempre que isso acontece desfalca os serviços internos, 
uma reforma na cozinha e no refeitório; a construção de vestiários para os funcionários.

As prisioneiras, em seu turno, falaram de melhorias na área de profissionais da saúde; de reforma no espaço dos banheiros; ampliação da circulação de ar nos quartos sempre mofados; cuidados com a água da chuva que sai pelas tomadas; cuidados para não proliferar insetos e bichos; e criação de um banheiro só para as crianças. Frisam a importância da utilização dos brinquedos que existem, todos doados, e que acabam guardados com a justificativa de evitar confusões entre as crianças, mas principalmente entre as mães. Todas são unânimes quanto à necessidade de mais programas infantis na televisão, que só repete "Galinha Pintadinha" e, principalmente, na necessidade de serem ouvidas sobre a permanência das crianças no Centro de Referência. Em concordância com a maioria, uma diz: "eu acho que cada um tinha que ter a sua escolha!" (Detenta, 2013). Em seguida outra detenta afirma: "aqui a gente tem o direito de permanecer calada!" (Detenta, 2013). Essas falas evidenciam o fato de que nem todas têm clareza do poder na determinação da vida dos filhos, para além das contingências em que se encontram. A maioria das falas mostra que as detentas não têm clareza de seus direitos. Apesar disso, a diretora da instituição e a psicóloga que ali trabalha disseram, em conversa com a pesquisadora, que as mulheres recebem as devidas informações sobre eles.

Frente a tudo que se escutou, pode-se delimitar como sugestões de reconstruções necessárias: garantir condições de salubridade e de recursos institucionais básicos; criar condições para que as crianças possam desenvolver atividades separadas de suas mães; criar condições para que as crianças possam sair da prisão algumas vezes, para passeios, até o juiz decidir a guarda, já que prisioneiras são as mães, como afirmam as autoridades, nas palavras de algumas; organizar vídeos educativos e recreativos para as crianças; possibilitar atividades de interesse das internas, separadas das crianças; favorecer o reconhecimento de que ser sujeito de direitos, em seu sentido mais básico, não se perde por estar reclusa em uma unidade prisional, ainda que alguns desses direitos fiquem suspensos; prestar atenção nas dificuldades que estruturalmente fazem parte de toda relação mãe/filho, agregando o singular de cada um e o geral das possibilidades institucionais.

\section{Considerações finais}

O estudo realizado coloca-nos frente aos encontros e desencontros entre o universal deontológico, as particularidades de uma instituição diferenciada, e a dimensão singular dos sujeitos que a constituem, 
que gritam para serem escutados no caso-a-caso. As falas das internas e dos funcionários nos convidam a refletir sobre as propostas humanizadoras do Centro de Referência: "se tiver 100 pessoas aqui, 90 pessoas aqui dentro preferem ir pra uma cadeia fechada, eu acho, pelo que a gente conversa aqui" (Detenta, 2013). "Minha filha é prematura. Nasceu cansada, tem problema de respiração, e aqui não é bom lugar. Prefiro mil vezes minha filha lá na casa de minha mãe" (Detenta, 2013).

Na justificativa do projeto do Centro de Referência (Minas Gerais, 2007 , p. 5), consta que a pretensão era criar uma unidade prisional baseando-se na ideia de que "ao promover o contato pele a pele", o vínculo afetivo é fortalecido. $\mathrm{E}$, consequentemente, há a promoção do "resgate de cidadania e responsabilidade das internas, uma vez que é reforçado o vínculo mãe-filho influenciando no perfil psicológico de ambos". No projeto fundador consta, ainda, que o objetivo da instituição é "garantir o aleitamento materno essencial para a criança no primeiro ano de vida, garantir o contato físico da criança com a mãe, contribuindo para fortalecer o vínculo psicoafetivo". Mas, a pesquisa mostrou que a questão não é simples, e essa garantia foi questionada pela maioria das mulheres que ali estava, segundo aquelas que participaram das conversações.

Pode-se dizer que estar ali, com os filhos, naquelas circunstâncias, associado à dificuldade inerente ao papel de ser mãe 24 horas, algumas delas distante de outros filhos, parecia ser vivido mais como um castigo que privilégio, tal como o projeto governamental pretendia. Se a instituição pode ser vista como um conjunto de regras que o sujeito continuamente desconstrói (Laurent, 2003), essas desconstruções do ideal institucional, por outro lado, podem apontar para renovações, transformações construtivas. O Centro de Referência representou um grande avanço no trato com mulheres gestantes e lactantes que cometem crimes, mas, como se sabe, um projeto de Lei, por si só, não garante melhorias. A experiência ensina que é a partir do funcionamento que são possíveis afirmações mais precisas, sobre qualquer instituição, para daí intervir com reajustes necessários ou avanços na proposta.

O Relatório de pesquisa foi enviado para leitura da direção da instituição, funcionárias e detentas que ainda estivessem lá, de modo a enviarem contribuições. Nenhuma contribuição foi enviada, e ele foi então encadernado e entregue às autoridades que dele possam tirar proveito. Uma cópia se encontra na Biblioteca da PUC Minas. 


\section{Referências}

Birman, J. (2006). Arquivo da agressividade em psicanálise. Natureza humana, 8(2), 357-379. Recuperado em 12 maio, 2015, de http://pepsic.bvsalud.org/pdf/nh/v8n2/v8n2a05.pdf

Brasil (2007a). Decreto Presidencial s/no, de 25 de maio de 2007. Institui o Grupo de Trabalho Interministerial com a finalidade de elaborar propostas para a reorganização e reformulação do Sistema Prisional Feminino. Diário Oficial da União, Poder Executivo. Brasília, DF.

Brasil (2007b). Centro pela Justiça e pelo Direito Internacional. Grupo de Estudos e Trabalho Mulheres Encarceradas. Relatório sobre mulheres encarceradas no Brasil. Presidência da República, Secretaria Especial de Políticas para as Mulheres. Brasília, DF. Recuperado em 04 abril, 2015, de http://asbrad.com.br/conte\%C3\%BAdo/relat\%C3\%B3rio_oea.p df.

Cottet, S. (2008). Criminologie lacanienne. Révue Mental. (M. Mezêncio, trad.), 21, 17-37. Recuperado em 12 maio, 2015, de http:/www.institutopsicanalise.mg.com.br/psicanalise/almanaqu e/04/textos/IV2.pdf.

Ferrari, I. F. (2012). Interface psicanálise e direito. In A. Rudge \& V. Besset (Org.). Psicanálise e outros saberes (pp. 67-86). Rio de Janeiro: Cia. de Freud.

Ferrari, I. F. \& Machado, M. N. (2014). Perfis de mães detentas convivendo com seus filhos. Pesquisas e Práticas Psicossociais, 9(2), 173-183. Recuperado em 03 maio, 2015, de http://www.seer.ufsj.edu.br/index.php/revista_ppp/article/view /923/682.

Freud, S. (2006). O mal-estar na civilização. In Freud, S. Edição standard brasileira das obras psicológicas completas de Sigmund Freud, v. XXI (pp. 81-177). Rio de Janeiro: Imago. (Trabalho original publicado em 1930).

Fusco, V. N. (2013). Filhos do cárcere: limites e possibilidades de garantir os direitos fundamentais dos filhos das mulheres privadas de liberdade no Brasil. (p. 168). Porto Alegre: Núria Fabris.

Gill, R. (2013). Análise de discurso. In M. Bauer \& G. Gaskell (Org.). Pesquisa qualitativa com texto, imagem e som: um manual prático ( 50 ed., pp. 254-270). Petrópolis, RJ: Vozes.

Lacan, J. (1998). Subversão do sujeito e dialética do desejo no inconsciente freudiano. In Lacan, J. Escritos. (pp. 807-842). Rio de Janeiro: Jorge Zahar Editor. (Trabalho original publicado em 1960).

Laurent, E. (2003). Acto e institución. Cuadernos de Psicoanálisis: Revista del instituto del Campo Freudiano en España, 27,46-50. 
Lei no 11.942, de 28 de maio de 2009 (2009). Dá nova redação aos arts. 14, 83 e 89 da Lei no 7.210, de 11 de julho de 1984 - Lei de Execução Penal, para assegurar às mães presas e aos recém-nascidos condições mínimas de assistência. Brasília. 2009. Recuperado em 10 maio, 2015, de http://www.planalto.gov.br/ccivil_03/_ato20072010/2009/lei/l11942.htm.

Lei no 7.210, de 11 de julho de 1984 (1984). Lei de Execução Penal, para assegurar às mães presas e aos recém-nascidos condições mínimas de assistência. Brasília. 1984. Recuperado em 10 maio, 2015, de http://www.planalto.gov.br/ccivil_03/leis/l7210.htm.

Miller, J. A. (1991). La agresividad en psicoanálisis de Jacques Lacan. In MILLER, Jacques-Alain et al. Agresividad y pulsión de muerte. (pp. 7-22). Medelin: f.f.m.

Miller, J. A; Alvarez, J. M. \& Chang, M. (2003a). La pareja y el amor: Conversaciones Clínicas con Jacques-Alain Miller en Barcelona. Buenos Aires: Paidós.

Miller, J. A. (2003b). Nota sobre a vergonha. Opção Lacaniana, 38, pp. 8-18.

Miller, J. A. (2005). El Otro que no existe y sus comités de ética. Buenos Aires: Paidós.

Minas Gerais. (2007). Secretaria de Estado de Defesa Social. Centro de Referência para as Gestantes em Privação de Liberdade e Creche do Sistema Prisional de MG: projeto. Belo Horizonte: Diretoria de Saúde a Atendimento Social.

Portaria Interministerial (2003). Portaria n. 1.777 de 09 de setembro de 2003. Institui o Plano Nacional de Saúde no Sistema Penitenciário. Ministério da Saúde e da Justiça, Brasília, DF. Recuperado em 02 maio, 2015, de http://bvsms.saude.gov.br/bvs/saudelegis/gm/2003/pri_1777_ 09_09_2003.html.

Ramirez, M. E. (2007). Órdenes de hierro: ensayos de psicoanálisis aplicado a lo social. Medelín: La Carreta.

Santiago, A. L. (2011). Entre a saúde mental e a educação: abordagem clínica e pedagógica de sintomas na escola nomeados por dificuldades de aprendizagem e distúrbios de comportamento. In A. L. Santiago \& R.H. Campos (Org.). Educação de crianças e jovens na contemporaneidade: pesquisas sobre sintomas na escola e subjetividade. Belo Horizonte: Ed. PUC Minas.

Salum, M. G. (2009). A psicanálise e o crime: causa e responsabilidade nos atos criminosos, agressões e violência na clínica psicanalítica contemporânea. Tese de doutorado, Programa de Pós-graduação em Teoria Psicanalítica da UFRJ, Rio de Janeiro, RJ, Brasil. Recuperado em 01 maio, 2015, de: 
http://teopsic.psicologia.ufrj.br/arquivos//documentos/55B47C 1482EA7B2ED886E80D22C0BF6B.pdf

\section{Endereço para correspondência}

\section{Ilka Franco Ferrari}

Pontifícia Universidade Católica de Minas Gerais

Programa de Pós-graduação em Psicologia da PUC Minas

Rua Itau, 525, Dom Cabral, CEP 30535-012, Belo Horizonte - MG, Brasil

Endereço eletrônico: francoferrari@terra.com.br

\section{Bárbara Morais Fam}

Pontifícia Universidade Católica de Minas Gerais

Programa de Pós-graduação em Psicologia da PUC Minas

Rua Itau, 525, Dom Cabral, CEP 30535-012, Belo Horizonte - MG, Brasil

Endereço eletrônico: barbaramfam@hotmail.com

Recebido em: 29/06/2015

Aceito para: 26/07/2016

\section{Notas}

* Professora nos cursos de graduação e pós-graduação da PUC Minas, Belo Horizonte, Brasil. Doutora pela Universidade de Barcelona, Espanha, membro da Escola Brasileira de Psicanálise e da Associação Mundial de Psicanálise, com sede em Paris, França. Bolsista de Produtividade em Pesquisa, Cnpq, nível PQ - 2.

** Mestre em Psicologia pelo Programa de Pós-graduação da PUC Minas, Belo Horizonte, Brasil. Psicóloga. 